\title{
Is Age Difference Between Partners Associated with Contraceptive Use Among Married Couples in Nigeria?
}

\begin{abstract}
CONTEXT: The likelihood that women use contraceptives may be reduced when they are considerably younger than their husband, because such age differences are often accompanied by disparities in social position, resources and life experiences, which may make marital relationships inherently unequal.
\end{abstract}

METHODS: Data from the 2008 Nigeria Demographic and Health Survey on 6,552 married couples in which the woman was aged 15-49 and the man was aged 15-59 were used to examine associations between partners' age difference and current contraceptive use. Associations were explored using multinomial logistic regression models that adjusted for women's and couples' characteristics. Separate analyses were conducted for couple methods (condoms, withdrawal and abstinence) and non-couple methods.

RESULTS: Ninety-eight percent of women were younger than their partner, and two-fifths were younger by 10 or more years. In bivariate analyses, women who were less than five years younger than their partner or were 5-9 years younger were more likely than those who were at least 10 years younger to be using a couple or non-couple contraceptive method (relative risk ratios, 1.4-2.2). However, these associations were no longer significant after adjustment for other characteristics. The measures that were most consistently related to use of couple and noncouple methods were education level, fertility intentions and household wealth.

CONCLUSION: Age differences between married partners are not associated with women's contraceptive use in Nigeria after adjustment for covariates. Further study is needed to understand this finding.

International Perspectives on Sexual and Reproductive Health, 2014, 40(1):39-45, doi: 10.1363/4003914
By Latifat Ibisomi

Latifat Ibisomi is lecturer, Department of Demography and Population Studies, University of the Witwatersrand, Johannesburg, South Africa.
An age difference between sexual partners is a social norm in most societies; typically, the man is older than the woman. The acceptability of unions in which the husband is considerably older than his wife is more variable, although relatively large age differences are found in patriarchal societies. Large age gaps are often accompanied by differences in maturity, life experiences, social position and financial resources, which may make relationships inherently unequal and a source of risk for women's health. ${ }^{1-5}$ For instance, asymmetries in age, education and economic circumstances compromise women's ability to negotiate safer sexual behavior. ${ }^{1-3,6-8}$

The studies that have examined associations between partners' age differences and contraceptive behavior have concentrated on adolescent females' nonmarital relationships and on whether protection was used against STIs (especially HIV). ${ }^{1-4,7-17}$ The emphasis on adolescents and on nonmarital relationships may divert attention from more common age asymmetries and from the risks that may exist in such relationships. For instance, age differences in marital relationships are usually of little public interest, unlike situations involving unmarried adolescents. Furthermore, there is the need to examine the role that contraceptive use may play in preventing unintended pregnancy in age-asymmetric relationships, given that contraception has been found to be an effective means of fertility control for various health, economic and social reasons. ${ }^{18}$

Examination of age differences between marital partners is of particular importance in Sub-Saharan Africa, where, as a result of gender imbalances and cultural influences, males are frequently in charge of what happens (or does not happen) within relationships, including sexual interactions and decisions regarding family size and contraceptive use. The limited decision-making power of women in this setting often impedes their ability to achieve their fertility goals. ${ }^{19-26}$ Moreover, in a patriarchal context, pronatal views tend to be stronger among men than among women, and husbands' real or perceived opposition to family planning may prevent wives who want to delay or stop childbearing from using contraceptives., $3,16,27-32$ The situation is no different in Nigeria, a patriarchal society where decision-making powers are traditionally vested in males. Nigeria is the most populous country in Africa, and women have an average of about six children, a level that has remained stable over the past two decades. ${ }^{33-36}$ Only about $15 \%$ of married women in Nigeria use any method of contraception, and about $20 \%$ of married women have an unmet need for contraception. ${ }^{37}$

Although some studies have shown that women in Nigeria have a degree of autonomy regarding contraceptive use, ${ }^{26,38}$ the evidence is inconclusive and women's degree of autonomy varies by region. Further, whether age differ- 
ences between marital partners are related to contraceptive use in the country is unknown. Given that age differences might influence relationship dynamics in ways that have adverse effects on women's health, and that male partners have enormous influence on fertility decisions and contraceptive use in Nigeria, the current study examines the association of age differences between married couples with women's contraceptive behavior. Specifically, the study seeks to determine whether a large age difference between marital partners is negatively associated with the woman's ability to use contraceptives.

\section{METHODS}

This study used matched couples data from the 2008 Nigerian Demographic and Health Survey (NDHS). The couples data set includes responses from 8,731 women aged 15-49 and their partners. We excluded 1,315 women who were pregnant, 203 who were infecund, 636 who had not had sex for at least six months and 25 whose partner was infecund. The resulting analytic sample consisted of 6,552 sexually active women-6,518 fecund women who had fecund partners and 34 women who had undergone sterilization as a family planning method. The latter group was left in the analytic sample because their use of sterilization as a family planning method may be related to the age difference between them and their partners.

The dependent variable was current contraceptive use. Women were asked if they were doing something or using something to delay or avoid becoming pregnant. Current contraceptive use was coded as 0 for nonuse, 1 for use of any couple method (condom, withdrawal or periodic abstinence) and 2 for use of any non-couple method (pill, IUD, injectable, diaphragm, female sterilization, implant or lactational amenorrhea). Although the methods grouped as "couple methods" include both modern and traditional methods, they all require the involvement and cooperation of the male partner. We examined these methods separately from other methods to explore the possible influence of male partners on women's contraceptive use and whether age differences between marital partners are associated with use of such methods.

*The wealth index is a composite measure of a household's living standard that is based on ownership of selected assets (e.g., televisions, bicycles), materials used for housing construction, and types of water access and sanitation facilities. The index, which is generated using principal components analysis, places individual households on a continuous scale of relative wealth. For this study, all households selected for the NDHS were divided into tertiles (low, medium, high) on the basis of their wealth index scores; to avoid sample bias, the resulting classifications were merged with the individual women's and couples' data before the sample was restricted. As a result, respondents in the analytic sample are not evenly distributed among wealth categories.

tLevels of economic development and educational attainment vary across the six regions of Nigeria. For example, the southern regions (particularly the South West region) are more economically and educationally advanced than the northern regions. In addition, the social and demographic characteristics of the North Central region are different from those of the other two northern regions, because the Federal Capital Territory is situated in the North Central region and is inhabited by people from all regions of the country. ${ }^{38,43}$

\begin{tabular}{|c|c|c|c|c|}
\hline $\begin{array}{l}\text { Age } \\
\text { difference }\end{array}$ & $\begin{array}{l}15-24 \\
(\mathrm{~N}=1,718)\end{array}$ & $\begin{array}{l}25-34 \\
(N=2,642)\end{array}$ & $\begin{array}{l}\geq 35 \\
(\mathrm{~N}=2,192)\end{array}$ & $\begin{array}{l}\text { All } \\
(\mathrm{N}=6,552)\end{array}$ \\
\hline$<5$ & 14.8 & 21.2 & 23.8 & 20.4 \\
\hline $5-9$ & 38.0 & 34.4 & 37.6 & 36.4 \\
\hline$\geq 10$ & 47.2 & 44.4 & 38.6 & 43.2 \\
\hline Total & 100.0 & 100.0 & 100.0 & 100.0 \\
\hline
\end{tabular}

Note:Differences in distributions by age are significant at $\mathrm{p}<.001$

The key independent variable was partners' age difference, which was derived by subtracting the woman's age from her partner's. Women were grouped according to whether they were older than their partner $(<0)$ or $0-4$, $5-9$, or 10 or more years younger. Since Nigeria is regionally, culturally, socially and economically diverse, and marital partners' fertility intentions may interact in complex ways, the analysis controlled for a number of related variables. Individual characteristics included in the analysis were the women's age (categorized as 15-24, 25-34, or 35 or older), religion (Muslim, Catholic, other Christian or other) and type of employment (professional, sales and service, agriculture and other, or none). Other variables were joint measures related to women and their partners, including household wealth (low, medium or high), ${ }^{*}$ place of residence (urban or rural), region (South West, North Central, North East, North West, South East or South South) ${ }^{\dagger}$ and type of marriage (monogamous or polygynous). Three final variables compared women with their spouses. A measure of educational attainment classified couples according to whether both had no education, both had a primary education, both had at least a secondary education, the woman was more educated than the man or the man was more educated than the woman. Another variable assessed whether the two partners had the same number of children, the woman had more children than her husband did (e.g., because she had children from a prior marriage) or the man had more children than his wife did. The last measure examined congruence in fertility intentions: whether both partners wanted a child soon, both wanted to space or limit births, the woman wanted a child soon but the man did not, the man wanted a child soon but the woman did not, or other mismatches in intentions. Individuals were classified as wanting a child soon if they wanted one within two years, were unsure of their desired timing or undecided about their fertility intentions; as wanting to space births if they wanted a child more than two years in the future; and as wanting to limit births if they wanted no future births

Descriptive, bivariate and multivariate analyses were carried out using Stata version 12. The bivariate and multivariate analyses used multinomial logistic regression modeling to assess the unadjusted and adjusted relative risk ratios of the association of age difference between partners 


\begin{tabular}{|c|c|c|c|}
\hline Characteristic & $\begin{array}{l}\% \\
(\mathrm{~N}=6,552)\end{array}$ & Characteristic & $\begin{array}{l}\% \\
(\mathrm{~N}=6,552)\end{array}$ \\
\hline Age & & Residence & \\
\hline $15-24$ & 25.2 & Urban & 31.3 \\
\hline $25-34$ & 40.4 & Rural & 68.7 \\
\hline \multirow[t]{2}{*}{$\geq 35$} & 34.4 & & \\
\hline & & Marriage type & \\
\hline Age differencet & & Monogamous & 68.9 \\
\hline$<0$ & 2.1 & Polygynous & 31.1 \\
\hline $0-4$ & 18.6 & & \\
\hline $5-9$ & 36.0 & Couple's no. of living children & \\
\hline \multirow[t]{2}{*}{$\geq 10$} & 43.3 & Same number & 53.1 \\
\hline & & Woman's > man's & 6.0 \\
\hline Religion & & Man's > woman's & 41.0 \\
\hline Islam & 58.2 & & \\
\hline Catholic & 7.4 & Couple's fertility intentions & \\
\hline Other Christian & 32.4 & Both want child soon & 18.3 \\
\hline \multirow[t]{2}{*}{ Other } & 2.1 & Both want to space/limit & 23.1 \\
\hline & & Woman wants child soon; man wants to space/limit & 13.8 \\
\hline Employment & & Woman wants to space/limit; man wants child soon & 14.8 \\
\hline None & 30.6 & Otherł & 30.0 \\
\hline Professional & 4.5 & & \\
\hline Sales/service & 48.8 & Contraceptive method & \\
\hline \multirow[t]{2}{*}{ Agriculture/other } & 16.1 & None & 81.7 \\
\hline & & Pill & 2.1 \\
\hline Education & & IUD & 1.2 \\
\hline Both none & 31.7 & Injectable & 3.6 \\
\hline Both primary & 9.5 & Diaphragm & 0.0 \\
\hline Both $\geq$ secondary & 18.4 & Condoms & 3.3 \\
\hline Man's > woman's & 29.7 & Female sterilization & 0.5 \\
\hline \multirow[t]{2}{*}{ Woman's > man's } & 10.7 & Periodic abstinence & 2.5 \\
\hline & & Withdrawal & 2.7 \\
\hline Household wealth & & Norplant & 0.1 \\
\hline Low & 36.5 & Lactational amenorrhea & 1.5 \\
\hline Medium & 29.7 & Other & 0.9 \\
\hline \multirow[t]{2}{*}{ High } & 33.8 & & \\
\hline & & Contraceptive method by category & \\
\hline Region & & None & 81.7 \\
\hline South West & 18.8 & Couple method§ & 9.9 \\
\hline North Central & 12.2 & Non-couple method & 8.5 \\
\hline North East & 16.6 & & \\
\hline North West & 34.3 & Total & 100.0 \\
\hline South East & 7.0 & & \\
\hline South South & 11.2 & & \\
\hline
\end{tabular}

†Husband's age minus wife's age. $\neq$ Either one partner wanted a child soon or wanted to space or limit births and the other was undecided or sterile, or both partners were sterile. §Condoms, periodic abstinence and withdrawal. Notes: All percentages are weighted. Percentages may not total 100.0 because of rounding.

with current contraceptive use (couple method vs. nonuse, and non-couple method vs. nonuse). As the proportion of women who were older than their partner was very small ( $2 \%$ ), such women were combined with women who were 0-4 years younger than their partner in the bivariate and multivariate analyses.

It is important to note the possibility of bias in the analytic sample, as men older than 59 were not interviewed in the NDHS. Thus, some women may have been interviewed but not included in the couples sample because their partner was older than 59. Tabulation reveals that the distribution of couples' age differences varied significantly by women's age. The percentage of women who were 10 or more years younger than their partner was smallest among women aged 35 or older (Table 1). This is likely due to the exclusion from the couples sample of some older women (especially those aged 45-49) whose partner was 10 or more years older than they were.
Analysis of the NDHS individual data set showed that $11 \%$ of women reported that their partner was older than 59 (and therefore ineligible for the couples data set). However, a comparison between women's reports of their partner's age and men's reports of their own age indicated that only $75 \%$ of women in the couples data set correctly reported their partner's age. It is thus difficult to reliably estimate the proportion of women who were excluded from the couples data set (or from the analytic sample of

TABLE 3. Relative risk ratios (and 95\% confidence intervals) from multinomial bivariate logistic regression analyses examining association between partners' age difference and contraceptive use

\begin{tabular}{lll} 
Age difference & Couple method vs.nonuse & Non-couple method vs.nonuse \\
\hline$<5$ & $1.85(1.46-2.36)^{* * *}$ & $2.22(1.68-2.93)^{* * *}$ \\
$5-9$ & $1.39(1.11-1.72)^{* *}$ & $1.72(1.34-2.20)^{* * *}$ \\
$\geq 10$ (ref) & 1.00 & 1.00
\end{tabular}

${ }^{* *} \mathrm{p}<.01 .{ }^{* * *} \mathrm{p}<.001$. Note: ref $=$ reference category. 
TABLE 4. Adjusted relative risk ratios (and 95\% confidence intervals) from multinomial logistic regression analyses examining associations between women's and couples' characteristics and contraceptive use, by method type

\begin{tabular}{|c|c|c|}
\hline Characteristic & $\begin{array}{l}\text { Couple method } \\
\text { vs.nonuse }\end{array}$ & $\begin{array}{l}\text { Non-couple method } \\
\text { vs.nonuse }\end{array}$ \\
\hline \multicolumn{3}{|l|}{ Age differencet } \\
\hline$<5$ & $0.99(0.76-1.30)$ & $0.92(0.67-1.26)$ \\
\hline $5-9$ & $1.01(0.79-1.28)$ & $1.11(0.83-1.47)$ \\
\hline$\geq 10$ (ref) & 1.00 & 1.00 \\
\hline \multicolumn{3}{|l|}{ Age } \\
\hline $15-24$ & $0.55(0.39-0.76)^{* * *}$ & $0.77(0.54-1.10)$ \\
\hline $25-34$ (ref) & 1.00 & 1.00 \\
\hline$\geq 35$ & $1.08(0.87-1.35)$ & $0.92(0.71-1.20)$ \\
\hline \multicolumn{3}{|l|}{ Religion } \\
\hline Islam (ref) & 1.00 & 1.00 \\
\hline Catholic & $1.42(0.91-2.20)$ & $1.23(0.76-1.99)$ \\
\hline Other Christian & $1.60(1.19-2.16)^{* *}$ & $1.04(0.73-1.49)$ \\
\hline Other & $1.44(0.68-3.02)$ & $1.41(0.54-3.63)$ \\
\hline \multicolumn{3}{|l|}{ Employment } \\
\hline None (ref) & 1.00 & 1.00 \\
\hline Professional & $1.35(0.84-2.15)$ & $0.82(0.50-1.35)$ \\
\hline Sales/service & $1.50(1.14-1.98)^{* *}$ & $1.03(0.75-1.44)$ \\
\hline Agriculture/other & $1.17(0.81-1.69)$ & $0.98(0.62-1.53)$ \\
\hline \multicolumn{3}{|l|}{ Couple's education } \\
\hline Both none (ref) & 1.00 & 1.00 \\
\hline Both primary & $2.17(1.38-3.41)^{* *}$ & $1.95(0.87-4.34)$ \\
\hline Both $\geq$ secondary & $2.08(1.32-3.29)^{* *}$ & $4.01(1.89-8.49)^{* * *}$ \\
\hline Man's > woman's & $2.09(1.43-3.05)^{* * * *}$ & $2.77(1.32-5.80)^{* *}$ \\
\hline Woman's > man's & $1.94(1.23-3.08)^{* *}$ & $3.49(1.62-7.54)^{* *}$ \\
\hline \multicolumn{3}{|l|}{ Household wealth } \\
\hline Low (ref) & 1.00 & 1.00 \\
\hline Medium & $1.57(1.14-2.16)^{* *}$ & $1.55(0.96-2.51)$ \\
\hline High & $2.84(1.96-4.11)^{* * *}$ & $2.81(1.68-4.68)^{* * *}$ \\
\hline \multicolumn{3}{|l|}{ Region } \\
\hline South West (ref) & 1.00 & 1.00 \\
\hline North Central & $0.86(0.66-1.17)$ & $0.31(0.22-0.46)^{* * *}$ \\
\hline North East & $0.45(0.30-0.66)^{* * * *}$ & $0.06(0.02-0.12)^{* * *}$ \\
\hline North West & $0.32(0.21-0.48)^{* * *}$ & $0.03(0.01-0.08)^{* * *}$ \\
\hline South East & $0.51(0.33-0.79)^{* *}$ & $0.97(0.66-1.43)$ \\
\hline South South & $0.68(0.49-0.94)^{*}$ & $1.04(0.75-1.44)$ \\
\hline \multicolumn{3}{|l|}{ Residence } \\
\hline Urban (ref) & 1.00 & 1.00 \\
\hline Rural & $0.90(0.70-1.14)$ & $0.82(0.63-1.08)$ \\
\hline \multicolumn{3}{|l|}{ Marriage type } \\
\hline Monogamous (ref) & 1.00 & 1.00 \\
\hline Polygynous & $0.79(0.58-1.06)$ & $0.36(0.22-0.59)^{* * *}$ \\
\hline \multicolumn{3}{|l|}{ Fertility intentions } \\
\hline Both want child soon (ref) & 1.00 & 1.00 \\
\hline Both want to space/limit & $5.38(3.57-8.11)^{* * *}$ & $2.37(1.62-3.46)^{* * *}$ \\
\hline Woman wants child soon; & & \\
\hline $\begin{array}{l}\text { man wants to space/limit } \\
\text { Woman wants to space/limit; }\end{array}$ & $2.01(1.21-3.34)^{* *}$ & $1.84(1.16-2.89)^{* *}$ \\
\hline $\begin{array}{l}\text { Woman wants to space/limit; } \\
\text { man wants child soon }\end{array}$ & $5.51(3.48-8.72)^{* * *}$ & $2.77(1.73-4.44)^{* * *}$ \\
\hline Other & $5.11(3.37-7.74)^{* * *}$ & $2.37(1.60-3.51)^{* * *}$ \\
\hline \multicolumn{3}{|l|}{ Couple's no. of living children } \\
\hline Same number (ref) & 1.00 & 1.00 \\
\hline Woman's > man's & $1.08(0.71-1.65)$ & $0.46(0.25-0.83)^{*}$ \\
\hline Man's > woman's & $1.08(0.82-1.41)$ & $0.81(0.58-1.13)$ \\
\hline
\end{tabular}

this study) because of the NDHS age restriction. In addition, information on duration of marriage with the current partner was not available in the data set and could not be controlled for in this analysis.

\section{RESULTS}

Descriptive

Women in the analytic sample had a mean age of 30.5. Ninety-eight percent were younger than their partners; $43 \%$ were younger by 10 or more years (Table 2, page 41). Nearly 60\% were Muslim, and 69\% were employed. In $32 \%$ of couples, neither partner had any education; in $10 \%$, both had only a primary education. In $40 \%$ of couples, educational attainment differed between partners; in three-quarters of these cases, the man had more education than the woman. The sample was distributed fairly equally among the three household wealth categories. About $63 \%$ of the couples were from a northern region, $69 \%$ lived in rural areas and $31 \%$ were in a polygynous union. In $53 \%$ of the couples, the two partners reported the same number of living children, while in $41 \%$ the man reported more children than his partner did. Fertility intentions were aligned in two-fifths of couples: In 18\%, both partners wanted a child within two years, while in $23 \%$ both wanted a child after two years or did not want any (or any more) children. Only 18\% of couples were using a contraceptive method; $10 \%$ (or $54 \%$ of couples practicing contraception) were using a method that required cooperation of the male partner (i.e., a couple method).

\section{Bivariate}

The key independent variable, partners' age difference, was negatively associated with contraceptive use (Table 3, page 41), indicating that the smaller the age difference between marital partners, the more likely the woman was to use a method. Specifically, couples with an age difference of less than five years or of 5-9 years were more likely than those with a difference of 10 or more years to be practicing contraception, whether they were using a couple method (relative risk ratios, 1.4-1.9) or a non-couple method (1.7-2.2). All of the other independent variables were also associated with current contraceptive use $(\mathrm{p}<.001$ for each; not shown).

\section{Multivariate}

The negative bivariate association between partners' age difference and contraceptive use was no longer significant in multivariate models that controlled for respondents' individual and joint characteristics with partners (Table 4). However, associations with both contraceptive categories were found for several other measures in the multivariate analyses. The likelihood that a woman and her partner were using a couple method rather than no method was greater if at least one partner had a primary or higher education than if both had no education (relative risk ratios, 1.9-2.2). Most of these associations were also apparent for non-couple methods (2.8-4.0). Household wealth was also positively associated with contraceptive use; couples with a medium level of wealth were more likely than couples with a low level of wealth to be using a couple method rather than no method (1.6), and those in the high wealth group had an elevated likelihood of using a couple meth- 
od or a non-couple method (2.8 for each).

Substantial regional differences emerged. Compared with women in the South West, women in all other regions except the North Central were significantly less likely to be using a couple method rather than no method (relative risk ratios, 0.3-0.7), and women in all three northern regions were less likely to be using a non-couple method (0.03-0.31). In addition, couples in which at least one partner wanted to space or limit childbearing were more likely than those in which both partners wanted a child soon to be using either type of contraceptive method rather than no method (1.8-5.5). The likelihood of contraceptive use was greater when the woman wanted to space or limit and her male partner wanted to have a child soon than when the reverse was the case.

Other variables were less consistently associated with contraceptive use. Respondents were less likely to be using a couple method than no method if they were aged 15-24 rather than aged 25-34 (relative risk ratio, 0.6), and more likely to be doing so if they were non-Catholic Christian rather than Muslim (1.6) or had a sales or service job rather than no job (1.5). Finally, women were less likely to be using a non-couple method rather than no method if they were in a polygynous rather than monogamous marriage (0.4), or if they reported having more children than their husband did rather than reporting the same number (0.5).

\section{DISCUSSION}

This study examined the association of age differences between marital partners with women's contraceptive behavior in Nigeria. Nearly all of the women in the study were younger than their partner, and two-fifths were younger by 10 or more years. This might be related to the patrilineal kinship organizations found in Nigeria. In patrilineal societies, age differences between partners tend to be relatively large, in part because such unions are arranged more frequently than would occur by chance or by the couples' own choices alone. , $^{4,5}$

Although the size of the age difference between partners was negatively associated with contraceptive use in the bivariate analysis, the association was no longer statistically significant after adjustment for women's and couples' characteristics. The reason for this unexpected finding is not apparent and was not explained by additional statistical tests. * However, a possible reason for the difference between the findings of this study and those of other studies $^{1-4,7-17}$ could be that negative reproductive health outcomes are more common in nonmarital relationships and among adolescents than within marriage and among older women, respectively. Moreover, women are often able to use contraceptives covertly, and exercise some degree of

*A number of models were created to explore the findings, including ones that examined possible interactions between age differences and other variables (particularly region) or that treated age difference as a continuous variable. Tests for multicollinearity were also conducted. Because the results of these models were essentially the same as those of the original analysis, only the simplest model is presented here. autonomy on use. Therefore, the influence of their husbands may not be as substantial as one might expect on the basis of age differences.

The exclusion of some women from the couples data set because their husband was older than 59 (and hence not surveyed) may have affected the study findings. For instance, if it is true that $11 \%$ of surveyed women had partners older than 59, then the differences across age-groups in the percentage distribution of women by spousal age difference may have been inflated in the analytic sample, especially among younger women. The influence of this bias on our findings is difficult to determine, but may have contributed to the lack of an association in the multivariate analysis between age differences and contraceptive use. This scenario and other possibilities (such as having a larger or smaller percentage of women whose partners were 10 or more years older than they were) remain a matter of conjecture. A survey that does not restrict data collection by male partners' age would shed further light on this issue.

Couples' educational attainment, wealth and fertility intentions were associated with the use of contraceptives. Further, there was a notably elevated likelihood of women using contraceptives to favor their own fertility intention when it did not match their partner's. This finding is a departure from previous studies that documented a reduced likelihood of contraceptive use by women if their fertility desires conflicted with their husband's real or perceived desires. ${ }^{23,24,29,39,40}$

Couples living in the South West region were generally more likely than those living elsewhere in the country to be using a method of contraception, a result consistent with the more favorable indicators of socioeconomic status and reproductive health among people in the South West region than among those in the other regions of the country. ${ }^{38,41-44}$ Women in polygynous unions were less likely than those in monogamous marriages to be using a non-couple method of contraception rather than using no method. This could be due, for example, to competition among co-wives for their husband's attention and resources. Having many children is reportedly a powerful strategy that women in polygynous unions use to get more leverage over their co-wives and their husbands, even if they themselves do not wish to have more children. ${ }^{38,41}$ Women aged 24 or younger were less likely than older women to be using a couple method of contraception rather than no method, probably because of ambivalence in their fertility intentions. ${ }^{45}$

In conclusion, this study found an association between large spousal age differences and women's contraceptive behavior in Nigeria in a bivariate analysis, but not in multivariate analyses. Further study, including use of qualitative methodology, is recommended to explore and better understand this finding.

\section{REFERENCES}

1. Luke N, Confronting the 'sugar daddy' stereotype: age and economic asymmetries and risky sexual behavior in urban Kenya, International Family Planning Perspectives, 2005, 31(1):6-14. 
2. Longfield $\mathrm{K}$ et al., Relationships between older men and younger women: implications for STIs/HIV in Kenya, Studies in Family Planning, 2004, 35(2):125-134.

3. Jewkes RK, Levin JB and Penn-Kekana LA, Gender inequalities, intimate partner violence and HIV preventive practices: findings of a South African cross-sectional study, Social Science \& Medicine, 2003, 56(1):125-134.

4. Darroch JE, Landry DJ and Oslak S, Age differences between sexual partners in the United States, Family Planning Perspectives, 1999 , 31(4):160-167.

5. Casterline JB, Williams L and McDonald P, The age difference between spouses: variations among developing countries, Population Studies, 1986, 40(3):353-374.

6. Gebreselassie T and Mishra V, Spousal agreement on waiting time to next birth in Sub-Saharan Africa, DHS Working Papers, Calverton, MD, USA: Macro International, 2007, No. 35.

7. DiClemente RJ et al., Sexual risk behaviors associated with having older sex partners: a study of black adolescent females, Sexually Transmitted Diseases, 2002, 29(1):20-24.

8. Kaestle CE, Morisky DE and Wiley DJ, Sexual intercourse and the age difference between adolescent females and their romantic partners, Perspectives on Sexual and Reproductive Health, 2002, 34(6):304-309.

9. Manlove J, Ryan S and Franzetta K, Contraceptive use patterns across teens' sexual relationships: the role of relationships, partners, and sexual histories, Demography, 2007, 44(3):603-621.

10. Manlove J, Terry-Humen E and Ikramullah E, Young teenagers and older sexual partners: correlates and consequences for males and females, Perspectives on Sexual and Reproductive Health, 2006, 38(4):197207.

11. Ford K, Sohn W and Lepkowski J, Characteristics of adolescents' sexual partners and their association with use of condoms and other contraceptive methods, Family Planning Perspectives, 2001, 33(3):100$105 \& 132$

12. Elo IT, King RB and Furstenberg FF, Jr., Adolescent females: their sexual partners and the fathers of their children, Journal of Marriage and the Family, 1999, 61(1):74-84.

13. Abma J, Driscoll A and Moore K, Young women's degree of control over first intercourse: an exploratory analysis, Family Planning Perspectives, 1998, 30(1):12-18.

14. Jejeebhoy SJ and Bott S, Non-consensual sexual experience of young people: a review of the evidence from developing countries, South \& East Asia Regional Working Paper, New Delhi: Population Council, 2003, No. 16.

15. Ajuwon AJ et al., Sexual coercion in young persons: exploring the experiences of rape victims in Ibadan, Nigeria, Health Education, 2004, 104(1):8-17.

16. Sturdevant MS et al., The relationship of unsafe sexual behavior and the characteristics of sexual partners of HIV infected and HIV uninfected adolescent females, Journal of Adolescent Health, 2001, 29(3 Suppl.):64-71

17. Vanoss Marín B et al., Older boyfriends and girlfriends increase risk of sexual initiation in young adolescents, Journal of Adolescent Health, 2000, 27(6):409-418.

18. Oye-Adeniran BA et al., Community-based study of contraceptive behavior in Nigeria, African Journal of Reproductive Health, 2006, 10(2):90-104.

19. Feyisetan BJ, Spousal communication and contraceptive use among the Yoruba of Nigeria, Population Research and Policy Review, 2000, 19(1):29-45

20. Ibisomi L and Odimegwu C, Understanding resolution of differential fertility preferences among couples in Nigeria, International Journal of Business and Social Science, 2011, 2(4):98-105.

21. DeRose LF and Ezeh AC, Decision-making patterns and contraceptive use: evidence from Uganda, Population Research and Policy Review, 2010, 29(3):423-439.

22. Keele JJ, Forste R and Flake DF, Hearing native voices: contracep- tive use in Matemwe Village, East Africa, African Journal of Reproductive Health, 2005, 9(1):32-41.

23. DeRose LF, Marriage, lineage, relative spousal power and fertility decline in Ghana, paper presented at the annual meeting of the Population Association of America, Boston, MA, USA, April 1-3, 2004.

24. DeRose LF, Dodoo FN and Patil V, Fertility desires and perceptions of power in reproductive conflict in Ghana, Gender $\&$ Society, 2002, 16(1):53-73.

25. Mason KO and Smith HL, Husbands' versus wives' fertility goals and use of contraception: the influence of gender context in five Asian countries, Demography, 2000, 37(3):299-311

26. Bankole A, Desired fertility and fertility behavior among the Yoruba of Nigeria: a study of couple preferences and subsequent fertility, Population Studies, 1995, 49(2):317-328.

27. Barden-O'Fallon JL and Speizer IS, Indonesian couples' pregnancy ambivalence and contraceptive use, International Perspectives on Sexual and Reproductive Health, 2010, 36(1):36-43.

28. Agadjanian V, Fraught with ambivalence: reproductive inten tions and contraceptive choices in a Sub-Saharan fertility transition, Population Research and Policy Review, 2005, 24(6):617-645.

29. Ezeh AC, The influence of spouses over each other's contraceptive attitudes in Ghana, Studies in Family Planning, 1993, 24(3):163-174.

30. Speizer IS, Are husbands a barrier to women's family planning use? The case of Morocco, Social Biology, 1999, 46(1-2):1-16.

31. Casterline JB, Perez AE and Biddlecom AE, Factors underlying unmet need for family planning in the Philippines, Studies in Family Planning, 1997, 28(3):173-191.

32. Dodoo FN, A couple analysis of micro-level supply/demand factors in fertility regulation, Population Research and Policy Review, 1993, 12(2):93-101.

33. Federal Office of Statistics and IRD/Macro International, Nigeria Demographic and Health Survey 1990, Columbia, MD, USA: IRD/Macro International, 1992.

34. National Population Commission and ORC Macro, Nigeria Demographic and Health Survey 1999, Calverton, MD, USA: National Population Commission and ORC Macro, 2000.

35. National Population Commission and ORC Macro, Nigeria Demographic and Health Survey 2003, Calverton, MD, USA: National Population Commission and ORC Macro, 2004.

36. National Population Commission and ICF Macro, Nigeria Demographic and Health Survey 2008, Calverton, MD, USA: National Population Commission and ICF Macro, 2009.

37. Measure DHS, STATcompiler, 2012, <http://statcompiler.com>, accessed July 12, 2012

38. Izugbara $C$ et al., Gendered interests and poor spousal contraceptive communication in Islamic northern Nigeria, Journal of Family Planning and Reproductive Health Care, 2010, 36(4):219-224

39. Dodoo F, Men matter: additive and interactive gendered preferences and reproductive behavior in Kenya, Demography, 1998, 35(2):229242

40. Bankole A and Singh S, Couples' fertility and contraceptive decision-making in developing countries: hearing the man's voice, International Family Planning Perspectives, 1998, 24(1):15-24.

41. Izugbara C et al., Change and Continuity in Reproductive Norms and Behavior: A Northern Nigeria Study, Nairobi, Kenya: African Population and Health Research Center, 2009

42. Makinwa-Adebusoye PK and Feyisetan BJ, The quantum and tempo of fertility in Nigeria, in: Macro International, Fertility Trends and Determinants in Six African Countries, Calverton, MD, USA: Macro International, 1994

43. Adegbola $\mathrm{O}$, Regional and socio-economic fertility differentials in Nigeria, 1981-1982, Interuniversity Programme in Demography Working Paper, Brussels, Belgium: Vrije Universiteit Brussel, 1987, No. 1987-6.

44. Feyisetan BJ and Bankole A, Fertility transition in Nigeria: trends and prospect, in: United Nations Population Division, Completing the 
Fertility Transition, New York: United Nations, 2009, pp. 461-478.

45. Koenig MA et al., Do current measurement approaches underestimate levels of unwanted childbearing? Evidence from rural India, Population Studies, 2006, 60(3):243-256.

\section{RESUMEN}

Contexto: La probabilidad de que las mujeres utilicen anticonceptivos puede verse reducida si las mujeres son considerablemente más jóvenes que sus maridos, porque la diferencia de edad suele ir acompañada de disparidades en la posición social, los recursos y las experiencias de vida, lo que puede hacer que las relaciones conyugales sean inherentemente desiguales. Métodos: Con el fin de examinar la relación entre la diferencia de edad en las parejas y el uso actual de anticonceptivos, se utilizaron datos de la Encuesta Demográfica y de Salud de Nigeria de 2008, referentes a 6,552 parejas casadas en las que la mujer tenía de 15 a 49 años de edad y el hombre de 15 a 59. Para ello se utilizaron modelos de regresión logística multinomial ajustados a las características de las mujeres y las parejas. Se condujeron análisis separados para métodos anticonceptivos de pareja (condones, retirada y abstinencia) y métodos individuales.

Resultados: El noventa y ocho por ciento de las mujeres resultaron ser más jóvenes que sus parejas; en dos quintos de los casos, la diferencia de edad fue de 10 años o más. En los análisis bivariados, las mujeres con una diferencia de edad respecto a sus parejas menor de cinco años, o de entre 5 y 9 años, mostraron una probabilidad mayor de estar utilizando un método anticonceptivo individual o de pareja (cocientes de riesgo relativo, 1.4-2.2) que las mujeres que eran al menos 10 años más jóvenes que sus parejas. Sin embargo, estas asociaciones dejaron de ser significativas una vez ajustadas a otras características. Las medidas que se relacionaron de manera más consistente con el uso de métodos individuales y de pareja fueron el nivel de educación, las intenciones de fecundidad y el nivel de riqueza de la familia.

Conclusión: Después de ajustar a las covariables, la diferencia de edad en parejas casadas de Nigeria no se relaciona con el uso de anticonceptivos por parte de las mujeres,. Es necesario seguir estudiando este hallazgo para comprenderlo mejor.

\section{RÉSUMÉ}

Contexte: La probabilité de pratique contraceptive peut être réduite chez les femmes considérablement plus jeunes que leur mari, car l'écart d'âge s'accompagne souvent de différences de rang social, de ressources et de vécu, qui peuvent rendre les relations conjugales fondamentalement inégales.

Méthodes: Les données de l'Enquête démographique et de santé nigériane de 2008 relatives à 6.552 couples mariés dans lesquels la femme était âgée de 15 à 49 ans et l'homme, de 15 à 59 ans, ont servi à l'examen des associations entre la différence d'âge entre les partenaires et la pratique contraceptive au moment de l'enquête. Les associations sont analysées au moyen de modèles de régression logistique multinomiale sous correction des caractéristiques des femmes et des couples. Des analyses séparées ont été effectuées pour les méthodes de couple (préservatif, retrait et abstinence) et les autres.

Résultats: Quatre-vingt-dix-huit pour cent des femmes étaient plus jeunes que leur partenaire; pour deux tiers, la différence était d'au moins 10 ans. Dans les analyses bivariées, les femmes qui étaient de moins de cinq ans ou de cinq à neuf ans les cadettes de leur partenaire se sont révélées plus susceptibles que celles plus jeunes d'au moins 10 ans de pratiquer une méthode contraceptive de couple ou autre (RC, 1,4-2,2). Ces associations ne sont cependant plus significatives après correction d'autres caractéristiques. Les mesures le plus régulièrement liées à la pratique des méthodes de couple ou autres sont le niveau d'instruction, les intentions de fécondité et la richesse du ménage.

Conclusion: Les différences d'âge entre partenaires mariés ne sont pas associées à la pratique contraceptive des Nigérianes après correction des covariables. Un examen approfondi permettra de mieux comprendre cette observation.

Author contact: libisomi@yahoo.com 